Revista Brasileira de Agricultura Irrigada v.8, nº 5, p.391 - 402, 2014

ISSN 1982-7679 (On-line)

Fortaleza, CE, INOVAGRI - http://www.inovagri.org.br

DOI: $10.7127 /$ rbai.v8n500253

Protocolo 253.14 - 31/05/2014 Aprovado em 16/08/2014

\title{
UNIFORMIDADE DE APLICAÇÃO DE FERTILIZANTES SOB UM SISTEMA DE GOTEJAMENTO SUBSUPERFICIAL
}

Fernando Nobre Cunha ${ }^{1}$, Nelmício Furtado da Silva ${ }^{2}$, Marconi Batista Teixeira ${ }^{3}$, José Joaquim de Carvalho ${ }^{4}$, Luciana Minervina de Freitas Moura ${ }^{5}$, Suiaine Ridan Pires de Melo ${ }^{6}$

\begin{abstract}
RESUMO
Objetivou-se com o trabalho avaliar a influência da fertirrigação com $\mathrm{N}$ e K em um sistema de irrigação localizada por gotejamento subsuperficial na cultura da cana-de-açúcar. $O$ experimento foi desenvolvido em condições de campo, na estação experimental do Instituto Federal Goiano - Câmpus Rio Verde - GO. O modelo de tubo gotejador utilizando no sistema: tubo gotejador Dripnet PC 16150 com vazão nominal de $1,0 \mathrm{~L} \mathrm{~h}^{-1}$, pressão de serviço de $100 \mathrm{kPa}$ e espaçamento entre gotejadores de $0,50 \mathrm{~m}$. As linhas gotejadoras foram enterradas à $0,20 \mathrm{~m}$ de profundidade do solo, entre dois sulcos. O monitoramento da vazão dos gotejadores $\left(\mathrm{L} \mathrm{h}^{-1}\right)$ permitiu a obtenção da vazão média dos gotejadores em condição subsuperficial. O CUC, CUE e CUD se mantiveram superiores a 75\%, quando na presença de fertirrigação, já na sua ausência estes foram superiores a $81 \%$. A aplicação de uréia e cloreto de potássio via água de irrigação causa mudança no sentido de distribuição do fluxo de saída da água maior do que a verificada na ausência destes fertilizantes.
\end{abstract}

Palavras-chave: vazão, fertilizantes solúveis, distribuição, irrigação

\section{UNIFORMITY OF APPLICATION OF FERTILIZERS UNDER A SYSTEM OF SUBSURFACE DRIP}

\begin{abstract}
This work aimed to evaluate the influence of fertirrigation with $\mathrm{N}$ and $\mathrm{K}$ in an irrigation system located by subsurface drip in cultivation of sugar cane. The experiment was carried at the experimental station of the Federal Institute Goiano - Campus Rio Verde - GO. The dripper tube model used in the system was the following: pipe dripper Dripnet PC 16150, with nominal flow rate of $1.0 \mathrm{~L} \mathrm{~h}^{-1}$, service pressure of 1 bar and spacing between drippers of $0.50 \mathrm{~m}$. The drippers line were buried at $0.20 \mathrm{~m}$ depth from the ground surface, between two

\footnotetext{
${ }^{1}$ Mestrando em Ciências Agrárias - Agronomia, Instituto Federal Goiano - Câmpus Rio Verde, Rodovia Sul Goiana, Km 01, CEP: 75.901-170, Rio Verde - GO, e-mail: fernandonobrecunha@ hotmail.com

${ }^{2}$ Mestrando em Ciências Agrárias - Agronomia, IFG - Câmpus Rio Verde, e-mail: nelmiciofurtado@ gmail.com ${ }^{3}$ Eng. Agrônomo, Prof. Dr. em Agronomia, IFGoiano - Câmpus Rio Verde, e-mail: marconibt@ gmail.com

${ }^{4}$ Pós-doutorando em Ciências Agrárias - Agronomia, IFGoiano - Câmpus Rio Verde, e-mail: josejoaquimcarvalho@yahoo.com.br

${ }^{5}$ Mestrando em Ciências Agrárias - Agronomia, IFG - Câmpus Rio Verde, e-mail: lucianaminervina@gmail.com

${ }^{6}$ Graduanda em Engenharia ambiental, IFG - Câmpus Rio Verde, e-mail: suiaineridan@ @otmail.com
} 
grooves. Flow monitoring of the drippers $\left(\mathrm{L} \mathrm{h}^{-1}\right)$ allowed to obtain the average flow rate of the drip irrigation system in subsurface condition in each test. The CUC, CUE and CUD remained higher than $75 \%$, when in the presence of fertirrigation, already in his absence these were always higher than $81 \%$. The application of urea and potassium chloride via irrigation water causes change in the direction of flow distribution output greater than that seen in the absence of these fertilizers water.

Keywords: flow, soluble fertilizers, distribution, irrigation

\section{INTRODUÇÃO}

O sistema de irrigação por gotejamento subsuperficial (IGS) ainda possui poucas informações quanto ao seu uso, principalmente em relação ao seu comportamento mediante a aplicação de nutrientes via água de irrigação e, se tratando de condições a nível de campo com instalação subsuperficial, estas informações são ainda mais escassas. Isso pode limitar o seu uso, tanto em relação a escolha de um modelo quanto ao manejo do sistema, apesar de todas as suas vantagens comparado aos demais sistemas de irrigação, das quais podemos citar a facilidade do manejo da irrigação e da cultura.

Nesse sistema, a superfície do solo estará com baixo teor de água reduzindo o desenvolvimento e germinação de plantas daninhas, o que facilita livre tráfego de máquinas e tratos culturais na superfície, mesmo com o sistema em funcionamento. Além disso, apresenta uma menor perda de água por evaporação direta da superfície do solo e grande potencial de automatização (LAMM et al., 2009; LIMA, et al., 2010; PARKES et al., 2010).

Como limitações do uso da IGS, existe a possibilidade de formação de vácuo no interior dos tubos e gotejadores, tornando possível a sucção de partículas de solo pelos emissores, além de intrusão radicular da cultura no orifício dos gotejadores, causando obstrução dos mesmos (COELHO et al., 2007; LIMA et al., 2010). Este método de irrigação vem sendo estudado por pesquisadores como (TEIXEIRA et al., 2008; COELHO, 2007; ENCISO et al., 2007; BARROS et al., 2009; RIBEIRO et al., 2010), que buscam estabelecer a melhor forma de instalar e manejar a irrigação subsuperficialmente.

Devido à alta uniformidade de aplicação da água proporcionada pela IGS e à aplicação da água diretamente na zona radicular das cultura, o uso dos fertilizantes via fertirrigação é favorecido na irrigação por gotejamento subsuperficial, logo melhora a eficiência no uso dos nutrientes, aumenta a produtividade com redução do custo operacional, proporciona maior rendimento e controle do desenvolvimento das plantas (ROBERTS, 2008; GIL et al., 2008; DANTAS NETO, 2006).

A formulação da solução a ser injetada no sistema de irrigação tem importante papel na uniformidade de distribuição do fertilizante aplicado via fertirrigação, assim a uniformidade de aplicação dos fertilizantes pode ser influenciada pela variação da concentração da solução, na taxa de injeção planejada e na vazão do sistema (OLIVEIRA et al., 2008).

Os sistemas de irrigação apresentam bom desempenho hidráulico, contudo, assim como todo sistema de irrigação localizada, há necessidade que o irrigante tome alguns cuidados quanto à qualidade da água, à fertirrigação e à limpeza do sistema, com o propósito de garantir maior durabilidade do equipamento com satisfatória uniformidade de aplicação de água 


\section{UNIFORMIDADE DE APLICAÇ̃̃O DE FERTILIZANTES SOB UM SISTEMA DE GOTEJAMENTO}

\section{SUBSUPERFICIAL}

(NASCIMENTO et al., 2009). Existem vários fertilizantes que podem ser utilizados via água de irrigação, levando em consideração: solubilidade em água (rápida e completa); elevada pureza; poder acidificador, baixo poder corrosivo; baixos riscos de salinidade do solo (OLIVEIRA et al., 2007).

Das principais fontes de $\mathrm{N}$, o nitrato de amônio ( $32 \%$ de $\mathrm{N}$ ) é o mais solúvel, seguido pelo nitrato de cálcio $(15,5 \%$ de $\mathrm{N})$ e a uréia. A fonte de $\mathrm{N}$ com maior mobilidade é o sulfato de amônio $(20 \%$ de $\mathrm{N})$; de $\mathrm{K}$ é o cloreto de potássio $\left(58 \%\right.$ de $\left.\mathrm{K}_{2} \mathrm{O}\right)$, seguido pelo nitrato de potássio e pelo sulfato de potássio (CIAVATTA, 2009). No tocante aos nutrientes essenciais, após o potássio, o nitrogênio é um dos mais absorvidos pela cana-de-açúcar (MALAVOLTA, 2006).

$\mathrm{Na}$ aplicação de nitrogênio é que a fertirrigação tem sido mais empregada, pois é conhecida a característica de comportamento desse nutriente no solo quanto a sua alta lixiviação e volatilização, já quanto à distribuição do $\mathrm{N}$ e do $\mathrm{K}$ no solo, diversos estudos mostraram elevada eficiência na fertirrigação com nitrogênio e potássio (URIU et al., 1977; VALE et al., 1997; QUINTANA, 2010).

Diante do exposto, este trabalho teve por objetivo avaliar a influência da fertirrigação com $\mathrm{N}$ e $\mathrm{K}$ em um sistema de irrigação localizada por gotejamento subsuperficial na cultura da cana-de-açúcar.

\section{MATERIAL E MÉTODOS}

$\mathrm{O}$ experimento foi desenvolvido em condições de campo, na estação experimental do Instituto Federal Goiano - Câmpus Rio Verde - GO. O clima da região é classificado conforme Köppen, como Aw (tropical), com chuva nos meses de outubro à maio, e com seca nos meses de junho à setembro. A temperatura média anual varia de 20 a $35{ }^{\circ} \mathrm{C}$ e as precipitações variam de 1.500 a $1.800 \mathrm{~mm}$ anuais e o relevo é suave ondulado $(6 \%$ de declividade).

O solo foi classificado como Latossolo Vermelho distroférrico (LVdf), de textura média (EMBRAPA, 2006). As parcelas experimentais são constituídas de três sulcos em linha dupla (plantio "em W" ou plantio em "abacaxi”) com espaçamento de 1,8 m entre linhas gotejadoras, $0,4 \mathrm{~m}$ entre sulcos e $8 \mathrm{~m}$ de comprimento, totalizando $64,8 \mathrm{~m}^{2}$ de área total por parcela. A variedade de cana-de-açúcar cultivada é a RB 85-5453, com uma lâmina de irrigação necessária para manter o solo na de capacidade de campo. Tratamentos: sem e com aplicação de fertilizante nitrogenada e potássica via água de irrigação (fertirrigação). O nitrogênio e o potássio foram aplicados ao longo do crescimento da cultura por meio do sistema de irrigação. A Tabela 1, mostra como foi realizada a fertirrigação (parcelamento) com $\mathrm{N} \mathrm{e} \mathrm{K}$ durante o ciclo de cultivo.

Tabela 1. Porcentagem do parcelamento de fertirrigação no decorrer do cultivo.

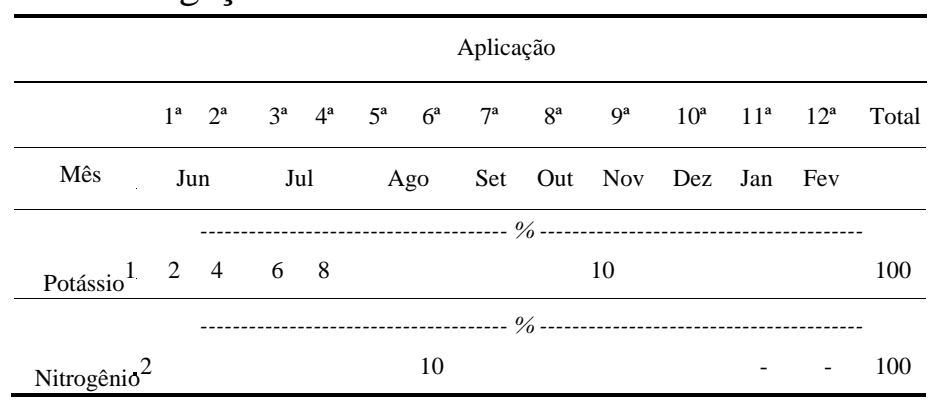

${ }^{1}$ Cloreto de potássio branco. ${ }^{2}$ Uréia.

O tempo de injeção dos fertilizantes corresponderam a 3,5 horas como forma de 
garantir a oferta de uma mesma quantidade de nutrientes para o tratamento com base em uma diluição mínima (Tabela 2). Para injeção dos fertilizantes no sistema de irrigação optou-se por um injetor Venturi que secionava os fertilizantes depois de dissolvidos em uma caixa reservatório com capacidade para $350 \mathrm{~L}$.

Tabela 2. Característica do fertilizante nitrogenado e potássico utilizados na fertirrigação.

\begin{tabular}{|c|c|c|c|c|c|c|}
\hline \multirow[t]{2}{*}{ Fertilizante } & \multicolumn{2}{|c|}{$\begin{array}{l}\text { Concentração } \\
\text { do nutriente } \\
\quad\left(\mathrm{g} \mathrm{kg}^{-1}\right)\end{array}$} & \multirow[t]{2}{*}{$\begin{array}{l}\text { Solubilidade } \\
\qquad\left(\mathrm{g} \mathrm{L}^{-1}\right) \\
\text { a } 20^{\circ} \mathrm{C}\end{array}$} & \multirow[t]{2}{*}{$\begin{array}{l}\text { Índice } \\
\text { salino }^{1}\end{array}$} & \multirow[t]{2}{*}{$\begin{array}{c}\text { Índice } \\
\text { salino / }^{2} \\
\text { unidade }^{2}\end{array}$} & \multirow[t]{2}{*}{$\begin{array}{c}\text { Índice de } \\
\text { acidez / } \\
\text { basicidade }\end{array}$} \\
\hline & $\mathrm{N}$ & Outros & & & & \\
\hline \multirow[t]{2}{*}{ Uréia } & 450 & - & 1000 & 75 & 1,7 & 71 \\
\hline & $\mathrm{K}_{2} \mathrm{O}$ & Outros & & & & \\
\hline $\begin{array}{l}\text { Cloreto de } \\
\text { potássio }\end{array}$ & 600 & $\begin{array}{c}480 \\
\text { de } \mathrm{Cl}\end{array}$ & 340 & 115 & 1,98 & Neutro \\
\hline
\end{tabular}

${ }^{1}$ Relativo ao valor do índice salino do nitrato de sódio $\left(\mathrm{NaNO}_{3}\right)$ considerado como 100. ${ }^{2}$ Índice salino dividido pelo teor de $\mathrm{N}$ e $\mathrm{K}_{2} \mathrm{O}$ no fertilizante x $10 .{ }^{3}$ Quantidade de $\mathrm{CaCO}_{3}$ necessária para neutralizar $100 \mathrm{~kg}$ do adubo. Fonte: Coelho (1994), Frizzone e Botrel (1994) e Vitti et al. (1994).

A aplicação dos fertilizantes via água de irrigação, foi realizada com injetor tipo Venturi; consistiu primeiramente da aplicação somente de água para o equilíbrio hidráulico do sistema de irrigação, e permitir maior uniformidade de distribuição dos fertilizantes, em seguida foi feito a injeção e ao término aplicou-se água para lavar o sistema de irrigação (0,5 h).

Foi utilizado um modelo de tubo gotejador com vazão nominal de $1 \mathrm{~L} \mathrm{~h}^{-1}$, diâmetro nominal $16 \mathrm{~mm}$, diâmetro interno 13 $\mathrm{mm}$, preção de operação 100 a $350 \mathrm{kPa}$ e espaçamento entre gotejadores de $0,50 \mathrm{~m}$.
A irrigação foi conduzida com base em tensiometria digital de punção com sensibilidade de $0,1 \mathrm{kPa}$, sendo as hastes tensiométricas instaladas nas profundidades de 0,20, $0,40,0,60$ e $0,80 \mathrm{~m}$ de profundidade e distâncias de $0,15,0,30,0,45$ e $0,60 \mathrm{~m}$ do tubo gotejador, com leitura do potencial matricial do solo $(\Psi \mathrm{m})$ registrada diariamente. Para determinar a necessidade de irrigação, utilizou-se tensão crítica de $50 \mathrm{kPa}$.

Para a medição da pressão de serviço, à entrada da linha de emissores, foi utilizado um manômetro de Bourdon com faixa de leitura de $0-4 \mathrm{Kgf} \mathrm{cm}^{-2}$. Para determinação do volume de água coletado durante cinco minutos de avaliação, utilizou-se uma proveta de $1 \mathrm{~L}$. Foram demarcados 32 gotejadores (um por parcela irrigada) para monitoramento mensal da irrigação, expressando-se os valores de vazão em $\mathrm{L} \mathrm{h} \mathrm{h}^{-1}$, assim foram realizadas as avaliações a cada 30 dias, num total de 12 avaliações.

O procedimento para leitura individual da vazão dos gotejadores consiste da pressurização do sistema, posicionamento de recipientes sob os respectivos gotejadores com uma defasagem de 5 segundos, retirada sequencial dos recipientes após 5 minutos com defasagem de 5 segundos, medição do volume coletado e tabulação dos dados.

O monitoramento da vazão dos gotejadores $\left(\mathrm{L} \mathrm{h}^{-1}\right)$ permitiu a obtenção da vazão média dos gotejadores em condição subsuperficial em cada ensaio utilizando-se a equação 1.

$$
q=\frac{M}{1000 \times t} 60
$$


em que:

$q$ - vazão do gotejador, $\mathrm{L} \mathrm{h}^{-1}$;

$M$ - massa de água coletada, $\mathrm{g}$; e

$t$ - tempo de coleta, min.

Depois de tabulados os dados de vazão, foram efetuados os cálculos da vazão e de uniformidade de aplicação de água pelos métodos mais utilizados na literatura, destacados nas equações 2 a 4 .

$$
C U C=100\left\{1-\frac{\sum_{i=1}^{n}\left|X_{i}-\bar{X}\right|}{n \cdot \bar{X}}\right\}
$$

CUC - Coeficiente de uniformidade de Christiansen, em \%.

$$
C U E=100\left(1-\frac{S}{\bar{X}}\right)
$$

CUE - Coeficiente de uniformidade estatístico, em $\%$.

$$
C U D=100\left(\frac{X_{25 \%}}{\bar{X}}\right)
$$

CUD - Coeficiente de uniformidade de distribuição, em \%.

em que:

$X_{i}$ - vazão de cada gotejador, em $\mathrm{L} \mathrm{h}^{-1}$;

$\bar{X}$ - vazão média dos gotejadores, em $\mathrm{L} \mathrm{h}^{-1}$;

$n$ - número de gotejadores observados;

$S$ - desvio-padrão dos dados de vazão, em $\mathrm{L} \mathrm{h}^{-1}$;

$X_{25 \%}$ - média de $25 \%$ do total de gotejadores, com as menores vazões, em $\mathrm{L} \mathrm{h}^{-1}$; e
$X_{12,5 \%}$ - média de $12,5 \%$ do total de gotejadores, com as maiores vazões, $\mathrm{em} \mathrm{L} \mathrm{h}^{-1}$.

Os dados obtidos foram submetidos à análise de variância pelo teste $\mathrm{F}$ ao nível de $1 \mathrm{e}$ $5 \%$ de probabilidade, e em casos de significância, foi realizada a análise de regressão e as médias foram comparadas entre si pelo teste Tukey à $5 \%$ de probabilidade.

\section{RESULTADO E DISCUSSÃO}

A vazão mostrou uma diferenciação ao longo das avaliações quando comparado com e sem fertirrigação. Do ponto de vista prático, a vazão média dos emissores pode ser considerada bom parâmetro para avaliar alterações quanto ao funcionamento adequado de emissores, como por exemplo, o seu entupimento (CARARO et al., 2006).

A vazão da primeira para última avaliação apresentou um decréscimo de $45 \%$ quando sob fertirrigação e na sua ausência este decréscimo não passou de $35 \%$. Observa-se que em praticamente $85 \%$ dos emissores sob fertirrigação, demonstraram valores discrepantes, ou seja, apresentaram algum distúrbio de vazão, enquanto, que sem fertirrigação este valor ficou em torno de $62,5 \%$, demonstrando menor quantidade de distúrbios e variabilidade; por esta razão ocorreu uma expansão da amplitude das vazões, o que levou consequentemente ao aumento da variação de vazão correspondente, o que é desfavorável para uma boa distribuição da água (Figura 1). 


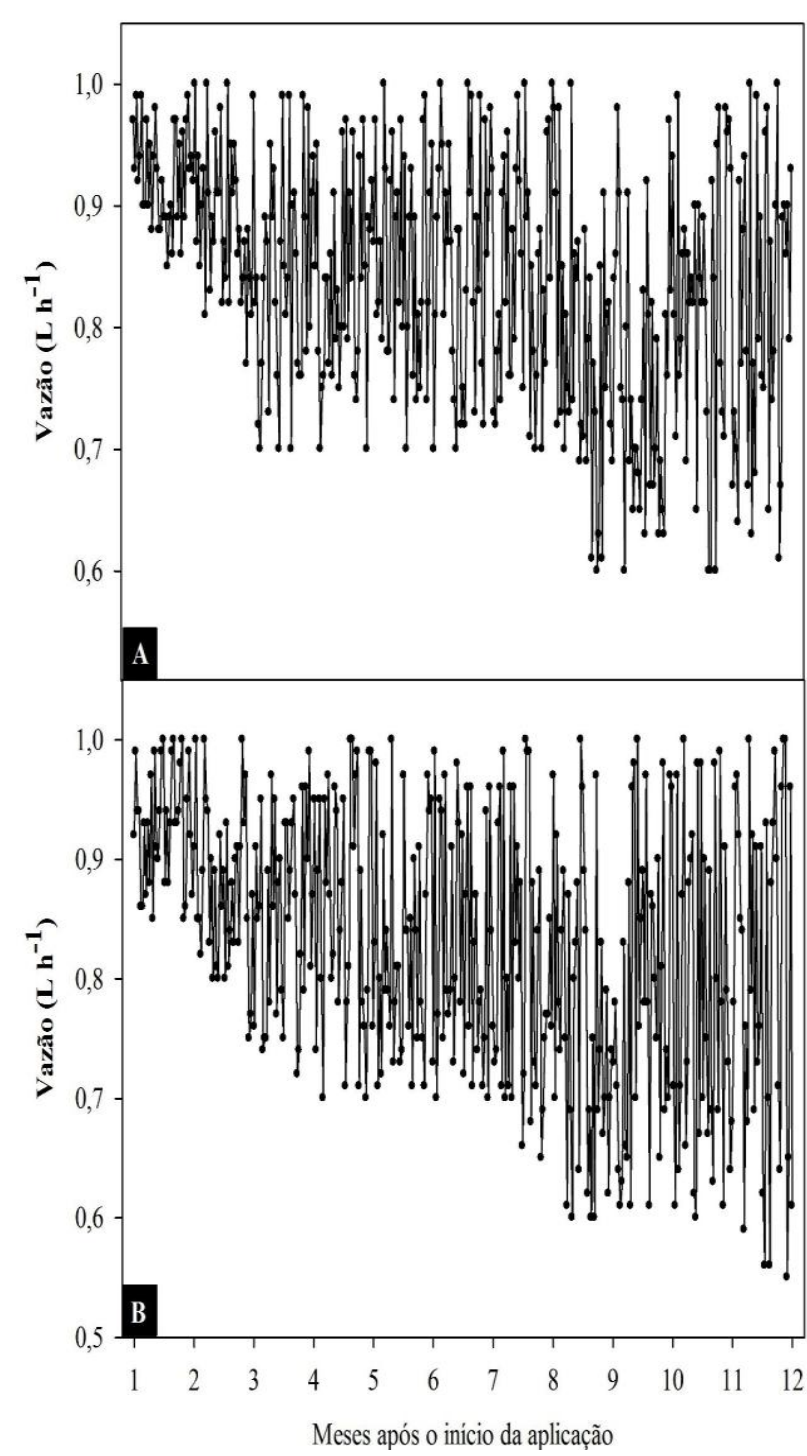

Figura 1. Vazão dos emissores de acordo com as avaliações realizadas mensalmente para o sistema de gotejamento. A - Sem Fertirrigação; B - Com Fertirrigação.

A uniformidade quando utilizado o CUC e CUE apresentaram diferença significativa em relação com e sem aplicação de uréia e cloreto de potássio via água de irrigação, enquanto, com a utilização do CUD essa diferença não foi constatada. O CV similarmente ao CUC e CUE apresentou diferença significativa em relação com e sem aplicação de uréia e cloreto de potássio via água de irrigação, a qual chegou a $12,5 \%$.
Tabela 3. Coeficientes de uniformidade e de variação com e sem aplicação de uréia e cloreto de potássio via água de irrigação.

\begin{tabular}{cccccccccc} 
& \multicolumn{8}{c}{ Média geral dos Coeficientes (\%) } \\
\cline { 2 - 9 } $\begin{array}{c}\text { Aplicação de } \\
\text { fertilização }\end{array}$ & CUC & CUE & & CUD & & CV & \\
& & & & & & & & \\
$\begin{array}{c}\text { Sem } \\
\text { fertirrigação } \\
\begin{array}{c}\text { Com } \\
\text { fertirrigação }\end{array}\end{array}$ & 90,90 & a & 89,19 & a & 86,42 & a & 10,81 & b \\
\hline
\end{tabular}

*Média com a mesma letra minúscula na coluna entre com e sem fertirrigação não indica diferença significativa pelo teste Tukey, a 5\% de probabilidade.

A uniformidade quando utilizado o CUC, se manteve superior a $88 \%$, quando na ausência de fertirrigação, já quando na sua presença seu valor foi de $83 \%$ uma redução de aproximadamente $5 \%$, a uniformidade se mostrou boa em ambos os casos conforme Mantovani (2002) que classifica o índice de uniformidade (CUC) acima de 80\% como bom (Figura 2), indicando, assim que o sistema está funcionando apropriadamente.

O CUC identificou pouca variação, discordância e distanciamento em relação a curva média, principalmente até a terceira avaliação, a partir da qual houve um aumento no afastamento, entre com e sem fertirrigação, isto foi ocorrendo, conforme foi aumentando o número de avaliações. Os valores de CUC sem fertirrigação foram superiores aos da curva média da sexta avaliação, quando sob fertirrigação os valores de CUC se mantiveram sempre abaixo desta curva desde a terceira avaliação.

O CUE na terceira avaliação demonstrou um valor menor sem do que com fertirrigação, entretanto, em seguida já foi reestabelecido o comportamento que prevaleceu nas avaliações, 
indicando uma maior propensão ao entupimento total quando na presença da fertirrigação, sendo observada a maior diferença entre sem e com na última avaliação, a qual foi de aproximadamente $5 \%$.

O CUD apresentou o comportamento mais instável, indicando variações mais acentuadas em determinadas avaliações, e em alguns casos pode-se verificar que a uniformidade demonstrou uma maior compatibilidade entre sem e com fertirrigação, ou seja, mostrando valores de uniformidade similares tanto para com quanto para sem fertirrigação.

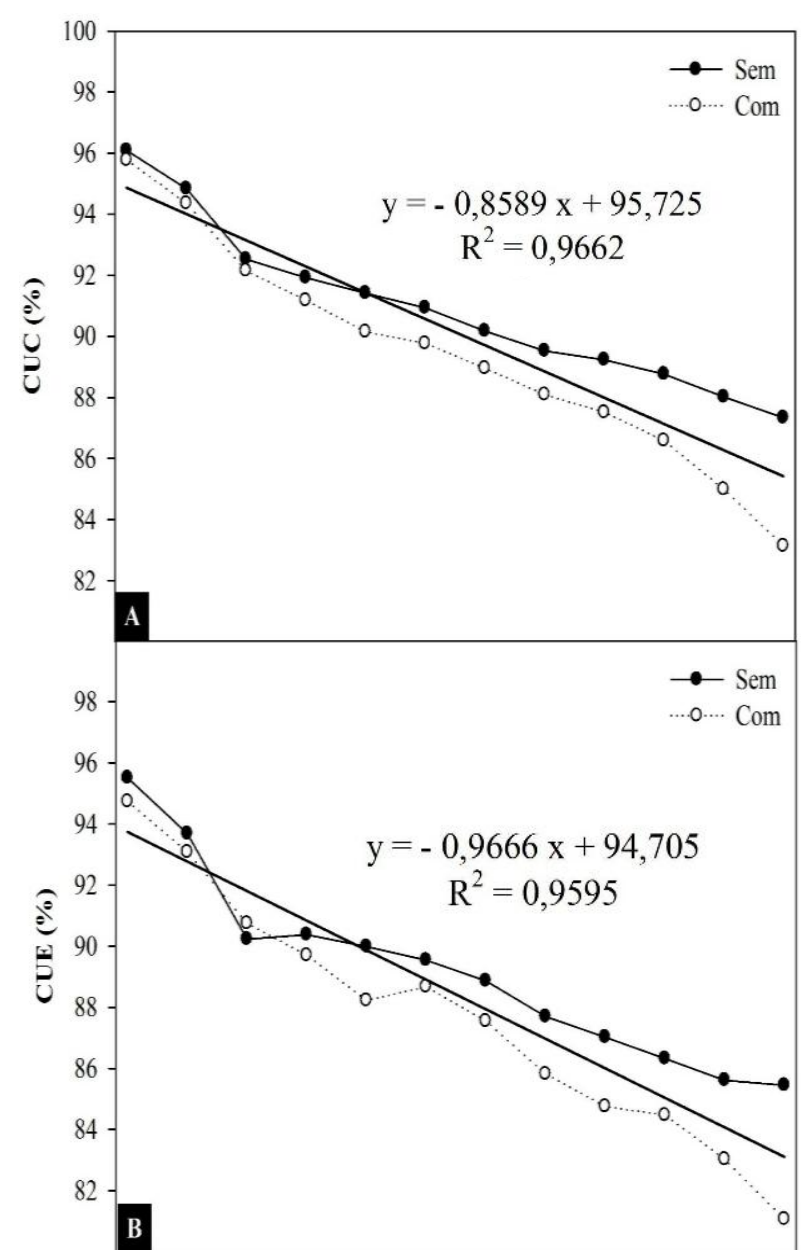

Figura 2. Coeficientes de uniformidade de aplicação de água (\%) em função das avaliações realizadas mensalmente para o sistema de gotejamento. A - CUC; B - CUE; C - CUD.

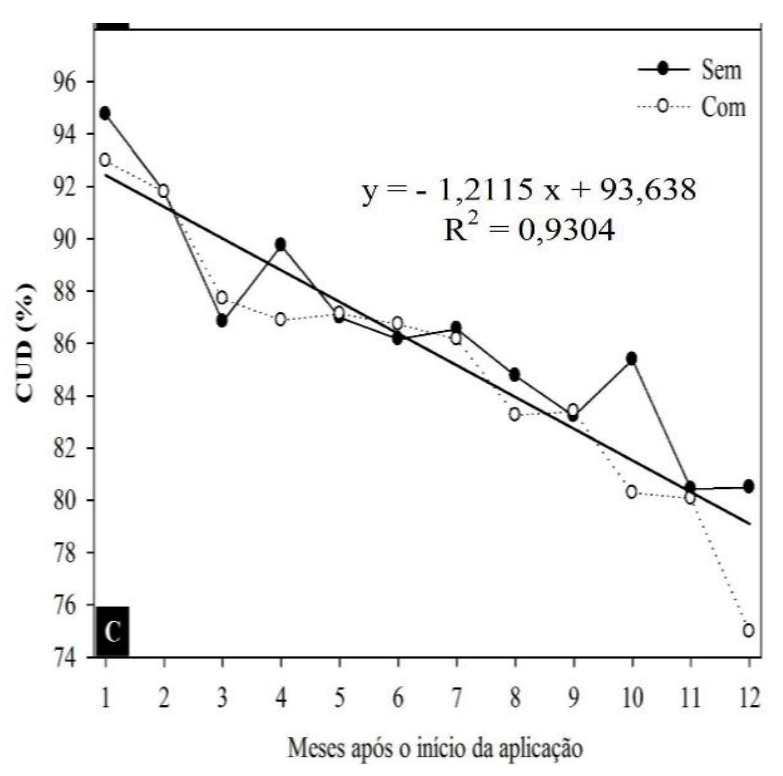

O CUE teve um comportamento similar ao do CUC, mas o CUE se mostrou excelente $(>90 \%)$ apenas nas 5 primeiras avaliações enquanto que o CUC indicou uma uniformidade excelente até a oitava avaliação; o CUE com fertirrigação foi de $81 \%$ e sem $86 \%$, demostrando uma boa uniformidade em ambos os casos (MANTOVANI, 2002).

$O$ coeficiente de uniformidade de distribuição (CUD) geralmente é mais sensível a pequenas variações do que o CUC e CUE, deste modo os seus valores da primeira $(93,1 \mathrm{e}$ 95\%) para a última avaliação (75 e $81 \%$ ), demonstraram uma redução de 18,1 e $14 \%$, com e sem fertirrigação respectivamente, sendo deste modo o impacto da fertirrigação na uniformidade próximo a $4 \%$, mostrando que a uniformidade de distribuição de água do equipamento está apresentando valores um pouco abaixo dos classificados como bom.

Keller \& Karmeli (1974) classificam os valores como excelente quando superiores a $90 \%$ e bom no intervalo de $85 \%$ a $90 \%$, no entanto segundo a classificação proposta por 
Mantovani (2002) esta uniformidade obtida tanto na presença quanto na ausência de fertirrigação é considerada como boa; assim pode-se dizer que de maneira geral o sistema de fertirrigação está funcionando adequadamente, pois seus valores mesmo sob fertirrigação ainda mantiveram-se acima de 75\% (Figura 2).

Os $\mathrm{CVq}$ da primeira para a última avaliação apresentaram uma diferença de aproximadamente 14 a $10 \%$ com e sem fertirrigação, sendo a máxima variação de 19 e 14\% respectivamente, muito acima de $10 \%$ considerado como valor limite do que se considera como ideal. Os coeficientes de variação com ou sem fertirrigação apresentaram-se crescente conforme a avaliação; deste modo observou-se um acentuado aumento na variação até a avaliação 3 seguido de uma estabilização nas avaliações 4 a 7 (sem fertirrigação) com valor médio de $\mathrm{CVq}$ entorno de 10\%; consequentemente verificou-se de maneira geral que até a avaliação 6, os valores de $\mathrm{CVq}$ foram inferiores a 10\% (Tabela 3), recebendo, assim, a classificação aceitável, segundo a norma ASABE EP 405 (ASABE, 2003).

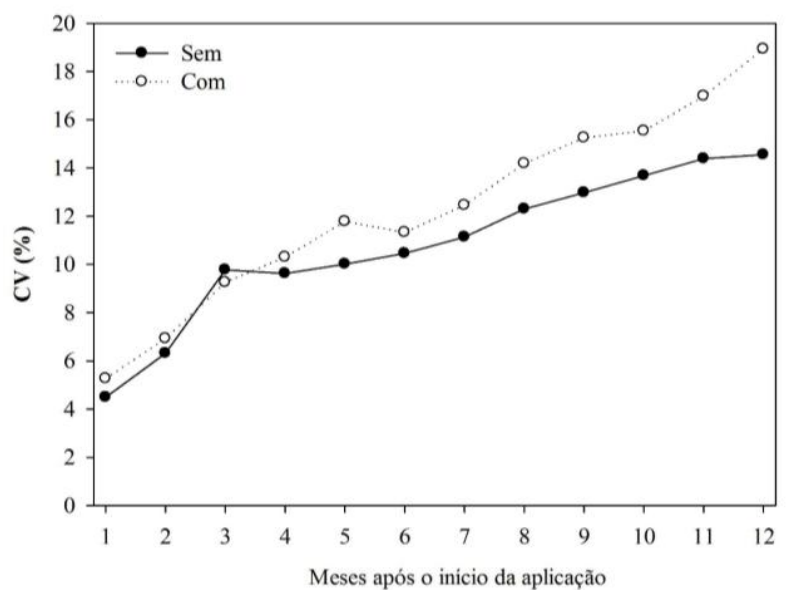

Figura 3. Coeficiente de variação de vazão em função das avaliações realizadas mensalmente para o sistema de gotejamento.
A aplicação de uréia e cloreto de potássio via água de irrigação provocou uma mudança no fluxo da água, principalmente na extremidade do emissor (diâmetro nominal) que tem o primeiro contato com os fertilizantes, indicando uma deposição gradual deste material, no interior do mesmo; o desvio no fluxo é mais amplo nesta extremidade, até aproximadamente o meio do emissor, equivalente ao raio nominal, onde este desvio se torna menos abrangente, proporcionado pela redução do diâmetro, podendo fazer com que a gota deixe de ser formada, chegando até a constituição de um fluxo mais continuo de emissão (maior velocidade de saída de água), indicando que esta alteração é em função de um entupimento parcial.

Ribeiro et al. (2012), testaram diversos gotejadores submetidos a condições extremas de uso e contataram que ocorreu maior suscetibilidade ao entupimento em razão do posicionamento do orifício dos gotejadores (para baixo), alguns gotejadores apresentaram valores de vazão após 288 horas de irrigação classificadas como inaceitáveis, mas de maneira geral, a arquitetura interna dos gotejadores avaliados foi o fator determinante na caracterização do processo de entupimento.

$\mathrm{O}$ entupimento parcial provoca uma quebra no sentido do fluxo da água provocando um caminho preferencial de saída da água (parte não obstruída) devido as barreiras impostas pelo material depositado, consequentemente causando a diminuição na vazão, o que implica numa menor uniformidade (Figura 4B). 


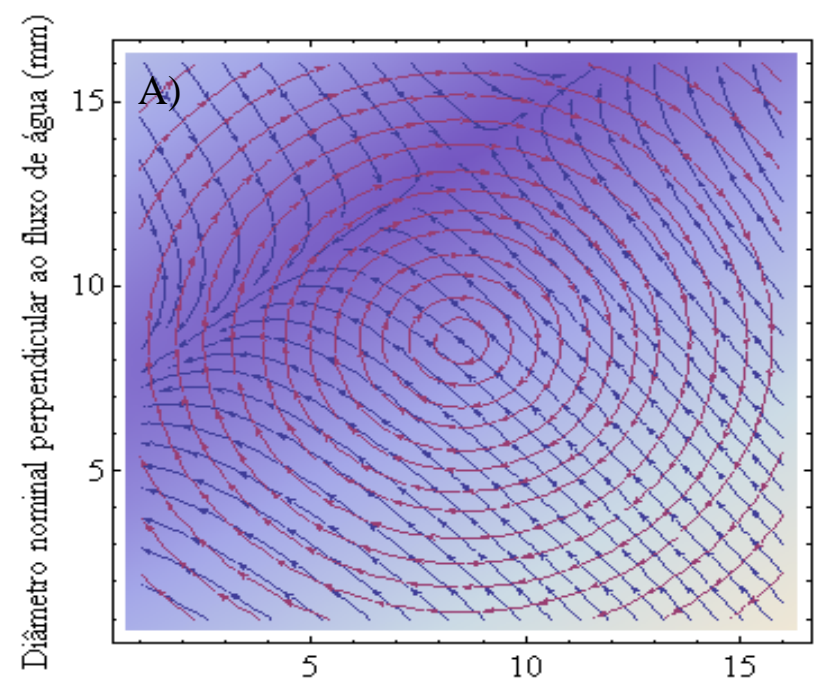

Diâmetro nominal no sentido do fluxo de água (mm)

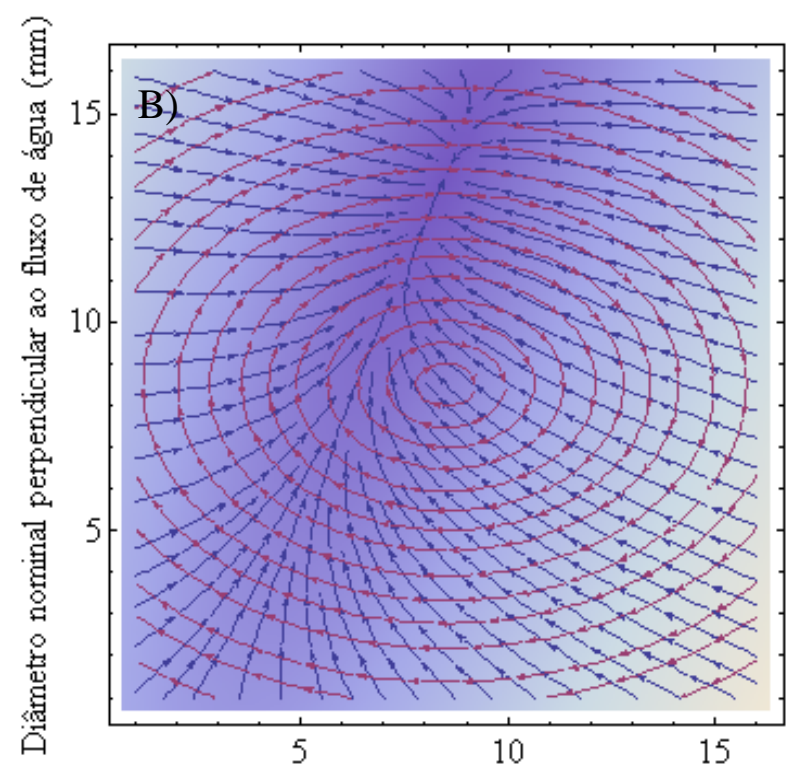

Diâmetro nominal no sentido do fluxo de água $(\mathrm{mm})$

Figura 4. Sentido de distribuição do fluxo de saída da água dos emissores (diâmetro nominal) com e sem aplicação de uréia e cloreto de potássio via água de irrigação.

Os fertilizantes quando não aplicados via água de irrigação, resulta em uma menor alteração no fluxo da água, ocorrendo, assim somente uma pequena modificação na distribuição na parte superior do diâmetro nominal do emissor (> 6,5 mm), também em função de um entupimento parcial, que neste caso é devido a partículas de solo (Figura 4A).
O bom desempenho do equipamento, verificado através da uniformidade mesmo quando sob fertirrigação, indica que o funcionamento não foi prejudicado por completo, sendo assim uma prática de manejo favorável, pois o seu êxito está ligado de maneira direta à uniformidade do sistema bem como da distribuição do fertilizante. Estes resultados estão de acordo com os encontrados por Dalri el al. (2014), onde segundo esses autores o entupimento de emissores enterrados sob a cultura da cana-de-açúcar após três anos de cultivo e sujeitos a condições de fertirrigação, concluíram que o uso provocou injúrias aos emissores apenas do ponto de vista de sua qualidade construtiva, afetando o $\mathrm{CVq}$ não havendo impedimento na estrutura do labirinto que prejudicasse a vazão.

\section{CONCLUSÃO}

A aplicação de uréia e cloreto de potássio via água de irrigação causa mudança no sentido de distribuição do fluxo de saída da água maior do que a verificada na ausência destes fertilizantes.

O desvio no fluxo é mais amplo e acentuado na extremidade que tem o primeiro contato com os fertilizantes, até aproximadamente no raio do emissor, onde este desvio se torna menos abrangente.

A fertirrigação teve $85 \%$ dos emissores com valores de vazão discrepantes (distúrbio de vazão) enquanto que sem fertirrigação este valor ficou entorno de $62,5 \%$.

O CUC, CUE e CUD se mantiveram superiores a $75 \%$, quando na presença de 
fertirrigação, já na sua ausência estes estiveram sempre superiores a $81 \%$.

Os CVq máximos ocorreram nas últimas avaliações com variação de 19 e $14 \%$ com e sem fertirrigação.

\section{AGRADECIMENTOS}

Os autores agradecem ao Ministério da Ciência e Tecnologia (MCT), ao Conselho Nacional de Desenvolvimento Científico e Tecnológico (CNPq) e à Coordenação de Aperfeiçoamento de Pessoal de Nível Superior (Capes), pelo apoio financeiro e estrutural.

\section{REFERÊNCIAS BIBLIOGRÁFICAS}

ASABE EP 405. Design and installation of microirrigation systems. ASAE Standards, St. Joseph, p.900-905, 2003.

BARROS, A, C.; FOLEGATTI, M. V.; SOUZA, C. F.; SANTORO, B. L. Distribuição de água no solo aplicado por gotejamento enterrado e superficial. Revista Brasileira de Engenharia Agrícola e Ambiental, v.13, n.6, p.700-707, 2009.

CARARO, D. C.; BOTREL, T. A.; HILLS, D. J.; LEVERENZ, H. L. Analysis of clogging in drip emitters during wastewater irrigation. Applied Engineering in Agriculture, St. Joseph, v.22, n.2, p.251-257, 2006.

CIAVATTA, S. F. Fertirrigação na produção e qualidade de mudas de Eucalyptus Spp. Nos períodos de inverno e de verão. Dissertação - Faculdade de Ciências Agronômicas, Universidade Estadual Paulista, Botucatu, 2009. 82p.

COELHO, A. M. Fertirrigação. In: COSTA, E. F.; VIEIRA, R. F.; VIANA, P. A. (Ed.). Quimigação: aplicação de produtos químicos e biológicos via irrigação. Brasília, DF: EMBRAPA-SPI, 1994. p. 201-227.

COELHO, R. D. Contribuições para a irrigação pressurizada no Brasil. 2007. 192p. Livre-Docência - Escola Superior de Agricultura "Luiz de Queiroz", Universidade de São Paulo, Piracicaba, 2007.

COELHO, R. D.; VILELA, L. A. A.; RESENDE, R. S.; TEIXEIRA, M. B.; SÁ, J. S. Entupimento de gotejadores em decorrência de pulsos de partículas sólidas na malha hidráulica. Irriga, Botucatu, v.12, p.108-122, 2007.

DALRI, A B.; PALARETTI, L. F.; CRUZ, R. L.; ZANINI, J. R.; FARIA, R. T.; SANTOS, G. O. Entupimento de emissores enterrados sob a cultura da cana-deaçúcar após três anos de cultivo em condições fertirrigadas. Irriga, Botucatu, Edição Especial 01, p. 62-71, 2014.

DANTAS NETO, J; FIGUEREDO, J. L. C; FARIAS, C. H. A; AZEVEDO, H. M; AZEVEDO, C. A. V. Resposta da cana-deaçúcar, primeira soca, a níveis de irrigação.e adubação de cobertura. Revista Brasileira de Engenharia Agrícola e Ambiental, v.10, n.2, p.283-288, 2006.

EMBRAPA. Centro Nacional de Pesquisa de Solos. Sistema Brasileiro de Classificação de Solos. 2 ed. Rio de Janeiro: Embrapa Solos, 2006.

ENCISO, J.; JIFON, J. A.; WIEDENFELD, B. Subsurface drip irrigation of onions: Effects of drip tape emitter spacing on yield and quality. In: Texas: A\&M University Agricultural Research and Extension Center Weslaco Texas, United States, Jul. 2007.

FRIZZONE, J. A.; BOTREL, T. A. Aplicação de fertilizantes via água de irrigação. In: VITTI, G. C.; BOARETTO, A. E. Fertilizantes fluidos. Piracicaba: Potafos, 1994. p. 227-260.

GIL, M.; SINOBAS, L. R.; JUANA, L.; SANCHEZ, R.; LOSADA, A. Emitter 
discharge variability of subsurface drip irrigation in uniform soils: Effect on waterapplication uniformity. Irrigation Science, v.26, p.451-458, 2008.

KELLER, J.; KARMELI, D. Trickle irrigation design parameters. Transactions of the ASAE, Saint Joseph, v. 17, n. 4, p. 678684, 1974.

LAMM, F. R.; ROGERS, D. H.; ALAM, M.; O'BRIEN, D. M.; TROOIEN, T. P. Twenty years of progress with SDI in Kansas. St. Joseph: American Society of Agricultural and Biological Engineers, 2009. 23 p. ASABE paper no. 095923. Disponível em: <http://www.ksre.ksu.edu/s di/Reports/2009/FRL20Yr09.pdf>. Acesso em: 26 abr. 2013.

LIMA, P. L. T.; MAGALHÃES, C. A. S.; LIMA, J. M. L.; LIMA; L. A.; CARBALHO, R. F. Trifluralina como inibidor de intrusão radicular em gotejamento subsuperficial. In: Congresso Brasileiro de Engenharia Agrícola, 39, 2010. Anais... Vitória 2010, CDROM.

MALAVOLTA, E. Manual de nutrição mineral de plantas. São Paulo. Ceres, 2006. $638 \mathrm{p}$.

MANTOVANI, E.C. Avalia: manual do usuário. Viçosa: DEA/UFV-PNP\&D/café Embrapa, 2002.

NASCIMENTO, J. M. S.; LIMA, L. A.; CARARO, D. C.; CASTRO, E. M.; SILVA, M. V. G. Avaliação da uniformidade de aplicação de água em um sistema de gotejamento para pequenas propriedades. Ciênc. agrotec. 2009, vol.33, n.spe, pp. 1728-1733.

OLIVEIRA, M. V. A. M.; VILLAS BOAS, R. L. Uniformidade de distribuição do potássio e do nitrogênio em sistema de irrigação por gotejamento. Engenharia Agricola 2008, vol.28, n.1, pp. 95-103.

OLIVEIRA, S. L. de; COELHO, E. F.;
BORGES, A. L. Irrigação e fertirrigação. Frutas do Brasil- Banana Produção, v.1, 2007.

PARKES, M.; YAO, W. W.; MA, X. Y.; LI, J. Simulation of point source wetting pattern of subsurface drip irrigation. Irrigation Science, v.29, p.331-339, 2010.

QUINTANA, K. A. Irrigação e fertirrigação por gotejamento para cana -de-açúcar na presença e ausência de boro. Tese Faculdade de Ciências Agrárias e Veterinárias, Universidade Estadual Paulista, Jaboticabal, 2010. 69f.

RIBEIRO, P. A. A; COELHO, R. D; TEIXEIRA, M. B. Entupimento de tubos gotejadores convencionais com aplicação de cloreto de potássio (branco e vermelho) via duas qualidades de água. Engenharia Agrícola, vol.30, n.2, pp. 279-287, 2010.

RIBEIRO, P. A. de A.; TEIXEIRA, M. B.; COELHO, R. D.; FRANCO, E. M.; SILVA, N. F. da; CARVALHO, L. C. C. de; ALVES, M. E. B. Gotejadores submetidos a condições críticas de qualidade da água. Brazilian Journal of Irrigation and Drainage IRRIGA, Botucatu, Ed. Especial, p. 368 - 379, 2012.

ROBERTS, T. L. Improving nutrients use efficiency. Turkish Journal of Agriculture and Forestry, v.32, p.177-182, 2008.

TEIXEIRA, M. B.; MELO, R. F. de; COELHO, R. D.; RETTORE NETO, O.; RIBEIRO, P. A. de A. Tratamento para desentupimento de gotejadores convencionais. Irriga, Botucatu, v. 13, n. 2, p. 235-248, 2008.

URIU, K.; CARLSON, R.M.; HENDERSON, D.W. Application of potassium fertilizer to prunes through a drip irrigation system. Seventh international agriculture plastic congress. Proceeding.... San Diego, 1977, p.211-214. 
Cunha et al.

VALE, F.R.do; GUEDES, G.A. de A.; VITTI, G. C.; BOARETTO, A. E.; GUILHERME, L.R.G.; FURTINI NETO, A.E. PENTEADO, S. R. Fertilizantes e Manejo da Fertilidade do Solo Lavras: fertirrigação. In: VITTI, G. C.; BOARETTO, UFLA/FAEPE, 1997. p.173-179. A. E. (Ed.). Fertilizantes fluidos. Piracicaba: Potafos, 1994. p. 262-281. 